\title{
Characterising the adipose-inflammatory microenvironment in male breast cancer
}

\author{
Tom Lees ${ }^{1,2}$, Angharad Cullinane1, Alexandra Condon', Abeer M Shabaan², Matthew P Humphries ${ }^{1, *},+$ \\ and Valerie Speirs ${ }^{1, *}$
}

'Leeds Institute of Cancer \& Pathology, University of Leeds, St James's University Hospital, Leeds, UK

2Department of Cellular Pathology, Queen Elizabeth Hospital Birmingham and University of Birmingham, Birmingham, UK

Correspondence should be addressed to V Speirs: v.speirs@leeds.ac.uk

*(M P Humphries and V Speirs contributed equally to this work)

†(M P Humphries is now at Centre for Cancer Research and Cell Biology, Queen's University Belfast, Belfast, UK)

\begin{abstract}
Male breast cancer (MBC) incidence seems to parallel global increases in obesity. The stromal microenvironment contributes to carcinogenesis; yet, the role of adipocytes in this is understudied in MBC. We identified four cohorts of male breast tissues diagnosed when obesity was rare (archival cohort) and more common (contemporary cohort). We examined the microenvironment of archival and contemporary cohorts of MBC, diagnosed 1940-1970 and 1998-2006, respectively, with two cohorts of, archival and contemporary gynaecomastia, diagnosed 1940-1979 and 1996-2011, respectively, serving as controls. We quantified adipocytes, crown-like structures (CLS) and the presence of CD8, $\alpha$ smooth muscle actin ( $\alpha$ SMA) and CD68+ macrophages in both cohorts, and determined how these affected survival, in the contemporary MBC cohort. In both MBC cohorts, mean adipocyte diameter was larger in the distant stroma compared with stroma close to the invading tumour $(92.2 \mu \mathrm{m}$ vs $66.7 \mu \mathrm{m})$. This was not seen in gynaecomastia. CLS were more frequent in both MBC cohorts than gynaecomastia $(44 / 55(80 \%)$ vs $11 / 18(61 \%), P<0.001)$. No relationship was found between CLS number and adipocyte size, although there were greater numbers of CLS in contemporary $M B C>$ archival MBC > gynaecomastia. CD8 and CD68 expression in the stroma was significantly associated with reduced survival, with no effects seen with $\alpha$ SMA. Changes in the adipose-inflammatory microenvironment may be a contributing factor to the increase seen in $\mathrm{MBC}$ diagnosis.
\end{abstract}

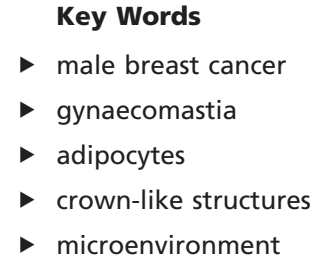

Endocrine-Related Cancer (2018) 25, 773-781

\section{Introduction}

Breast cancer (BC) affects both genders, although it is rare in men with a global incidence of around 8000 (Humphries et al. 2015). Anecdotal evidence that the number of men receiving a $\mathrm{BC}$ diagnosis is growing is supported by population-based evidence informed from data collected from the National Cancer Institute's Surveillance, Epidemiology and End Results (SEER) database. This showed a significant increase in male BC from 0.86 to 1.08 per 100,000 population in the United States over 25 years (1973-1998) (SEER 2014). Our group confirmed this in an interrogation of the 2014 SEER dataset (Humphries et al. 2015) and have previously shown parallel rises using data obtained in the United Kingdom, Canada and Australia (Speirs \& Shaaban 2009). 
Reasons for the gradual rise in incidence are not known; however, we have shown recently that this appears to parallel rising levels of obesity (Humphries et al. 2015).

In terms of pathobiological and physiological characteristics, male breast cancer (MBC) has been likened to BC in post-menopausal women (Anderson et al. 2010). Post-menopausal BC is linked to obesity, due to a combination of peripheral aromatisation of androgens in adipose tissue, leading to increased systemic oestrogen levels and associated metabolic abnormalities (Chen et al. 2016). Inflammation is also associated with obesity with chronic inflammation observed in a number of different types of cancer, including breast (De Pergola \& Silvestris 2013). Furthermore, macrophages that contribute to the inflammatory state are frequently recruited into adipose tissue (Johnson et al. 2012). Dead adipocytes are a pathological hallmark of obesity, which is characterised by CD68-positive macrophages surrounding these dead cells, forming so-called crown-like structures (CLS) (Cinti et al. 2005, Murano et al. 2008). CLS have been examined in female breast tissue and are significantly more abundant in obese compared to lean women (Mullooly et al. 2017). In female BC, presence of CLS in adipose tissue from $\mathrm{BC}$ resections was associated with worse distant relapse-free survival (Iyengar et al. 2016), while in women undergoing breast conserving surgery, a positive association was observed between body composition, size of breast adipocytes and incidence of CLS (Vaysse et al. 2017).

As well as their role in CLS formation, macrophages are frequently the most abundant inflammatory infiltrate in the tumour microenvironment (Balkwill et al. 2005). When present in high numbers, they are associated with poorer disease-free survival in women, particularly in the ER+ setting (Medrek et al. 2012, Gwak et al. 2015, Zhao et al. 2017). Tumour-infiltrating lymphocytes (TILs) are also common in the BC tumour microenvironment (Savas et al. 2016). Studies on large numbers of patients have indicated that these are typically associated with improved outcome in patients with early stage triple-negative and HER2-positive BC (Yamaguchi et al. 2012, Loi et al. 2013, Ali et al. 2014). Despite the infrequency of the HER2-postive phenotype in MBC (Humphries et al. 2017), higher TIL density has been reported in this subtype in men (Vermeulen et al. 2017). In this same study, examination of the relationship between TIL density, through review of haematoxylin and eosin (H\&E)-stained sections showed that lower TIL densities correlated with reduced overall survival (Vermeulen et al. 2017).
We have previously proposed that not only is obesity a risk factor for male $\mathrm{BC}$, but that increasing obesity trends may contribute to its increased incidence (Humphries et al. 2015). Therefore, the aim of this study was to examine and characterise components of the adipose-inflammatory tumour microenvironment in a contemporary and an archival series of male BCs, the latter diagnosed during 1940s-1970s, at a time when obesity was virtually non-existent in the United Kingdom.

\section{Materials and methods}

\section{Cases}

Following ethical approval (06/Q1205/156; 15/YH/0025), tissues were obtained from patients diagnosed at Leeds Teaching Hospitals NHS Trust or from tissue donated to the Breast Cancer Now Tissue Bank (http:// breastcancernow.org/breast-cancer-research/breastcancer-now-tissue-bank). Tissue sections obtained after September 2006 were taken with informed consent from patients prior to surgical resection. Forty-nine formalin-fixed paraffin-embedded (FFPE) contemporary MBC (cMBC) tissue sections were obtained, diagnosed between 1996 and 2008, plus a further 37 archival FFPE MBC tissue sections (aMBC), diagnosed between 1940 and 1978. As we have previously reported in female cases from this archival series (Dowsett et al. 2014), compared to modern day standards, clinicopathological information recorded at this time is patchy, with details on grade, node status and in some cases, the diagnosis, frequently omitted from clinical reports accompanying aMBC cases. More in-depth data such as BMI are completely lacking. Consequently, digital images were reviewed with a consultant histopathologist (AMS) to identify which could be suitably utilised as comparative MBC cases with the contemporary cohort. Of the 37 archival cases obtained from the Breast Cancer Now Tissue Bank (http://breastcancernow.org/breast-cancer-research/ breast-cancer-now-tissue-bank), six were identified as invasive carcinomas and the others were identified as having a benign pathology or were normal male breast tissue. Eighteen cases were identified as gynaecomastia, so were allocated as a control cohort (aGC) for comparison with MBC sections. Gynaecomastia was classified into active, intermediate or late type as previously described (Bannayan \& Hajdu 1972). Active was classified as florid immune infiltration and ductal hyperplasia, whereas late type cases were observed to have fewer ducts and 
frank fibrosis within the stroma. Intermediate type represented cases with features of both. Thirteen archival cases did not have a diagnosis of invasive carcinoma or gynaecomastia, so were excluded from the analysis. A tissue microarray (TMA) was obtained from Queen Elizabeth Hospital, Birmingham, UK, containing a cohort of 70 patients diagnosed with gynaecomastia. This TMA was constructed with two tissue cores per case taken from FFPE material and used as a control for the cMBC sections (cGC) for immunohistochemical analysis of various biomarkers. The baseline characteristics of the cases used are summarised in Table 1.

\section{Immunohistochemistry}

FFPE tissue blocks were sectioned serially at $5 \mu \mathrm{m}$ and mounted onto Xtra Slides (Leica). After drying $\left(37^{\circ} \mathrm{C}\right.$ overnight), heat-induced antigen retrieval was carried out as previously described (Humphries et al. 2017). Briefly, this was achieved by pressure-cooking in 10\% antigen retrieval Access Revelation Solution - 10x solution - at $125^{\circ} \mathrm{C}$ (Menarini Diagnostics, Wokingham, UK). CD68, CD8 and $\alpha$ SMA (all 1:100; Dako) were applied to slides and incubated for 30, 60 and $30 \mathrm{~min}$, respectively. Novolink Polymer Detection System kit

Table 1 Clinicopathological details of the cases analysed.

\begin{tabular}{|c|c|c|c|c|}
\hline \multirow[b]{2}{*}{ Characteristic } & \multicolumn{2}{|c|}{ Male breast cancer (number (\%)) } & \multicolumn{2}{|c|}{ Gynaecomastia (number (\%)) } \\
\hline & Contemporarya $^{a}$ & Archivalb & Contemporary & Archival \\
\hline \multicolumn{5}{|l|}{ Age (years) } \\
\hline $13-30$ & $0(0)$ & $0(0)$ & $49(70)$ & $4(22.2)$ \\
\hline $30-39$ & $0(0)$ & $0(0)$ & $8(11.4)$ & $0(0)$ \\
\hline 40-49 & $3(6.1)$ & $0(0)$ & $7(10)$ & $1(5.6)$ \\
\hline $50-59$ & $6(12.2)$ & $2(33.3)$ & $2(2.9)$ & $0(0)$ \\
\hline $60-69$ & $10(20.4)$ & $0(0)$ & $2(2.9)$ & $1(5.6)$ \\
\hline $70-79$ & $15(30.6)$ & $1(16.7)$ & $2(2.9)$ & $1(5.6)$ \\
\hline $80-89$ & $15(30.6)$ & $0(0)$ & $0(0)$ & $0(0)$ \\
\hline Unknown & $0(0)$ & $3(50)$ & $0(0)$ & $11(61.1)$ \\
\hline \multicolumn{5}{|l|}{ Diagnosis (year) } \\
\hline 1940-1949 & N/A & $2(33.3)$ & N/A & $1(5.6)$ \\
\hline 1950-1959 & N/A & $2(33.3)$ & N/A & $1(5.6)$ \\
\hline 1970-1979 & N/A & $2(33.3)$ & N/A & $16(88.9)$ \\
\hline 1996-2000 & $18(36.7)$ & N/A & $3(3.5)$ & N/A \\
\hline 2001-2005 & $16(32.7)$ & N/A & $13(15.1)$ & N/A \\
\hline $2006-2008$ & $12(24.5)$ & N/A & $51(59.3)$ & N/A \\
\hline 2009-2011 & $0(0)$ & N/A & $3(4.3)$ & N/A \\
\hline Unknown & $3(6.1)$ & $0(0)$ & (0) & $0(0)$ \\
\hline \multicolumn{5}{|l|}{ Histology } \\
\hline Ductal & $43(87.8)$ & $5(83.3)$ & N/A & N/A \\
\hline Papillary & $4(8.2)$ & $1(16.7)$ & & \\
\hline Lobular & $1(2)$ & $0(0)$ & & \\
\hline Unknown & $1(2)$ & $0(0)$ & & \\
\hline \multicolumn{5}{|l|}{ Grade } \\
\hline 1 & 7 (14.3) & $0(0)$ & N/A & N/A \\
\hline 2 & 33 (67.3) & $4(66.7)$ & & \\
\hline 3 & 8 (16.3) & $2(33.3)$ & & \\
\hline Unknown & $1(2)$ & $0(0)$ & & \\
\hline \multicolumn{5}{|l|}{ Lymph nodes } \\
\hline+ & $15(30.6)$ & $2(33.3)$ & N/A & N/A \\
\hline- & 32 (65.3) & $3(50)$ & & \\
\hline Unknown & $2(4.1)$ & $1(16.7)$ & & \\
\hline \multicolumn{5}{|l|}{ Size $(\mathrm{mm})$} \\
\hline$\leq 20$ & $31(63.3)$ & $2(33.3)$ & N/A & N/A \\
\hline$>20$ & $14(28.6)$ & $1(16.7)$ & & \\
\hline Unknown & $4(8.2)$ & $3(5)$ & & \\
\hline \multicolumn{5}{|c|}{ Gynaecomastia type } \\
\hline Active & $\mathrm{N} / \mathrm{A}$ & $\mathrm{N} / \mathrm{A}$ & $6(33.3)$ & Information not available \\
\hline Intermediate & & & $6(33.3)$ & \\
\hline Late & & & $6(33.3)$ & \\
\hline
\end{tabular}

aAll ER $\alpha$ positive; bER $\alpha$ status not defined. N/A, not available. 
(Leica Biosystems) was used for visualisation of bound antigen following the manufacturer's protocol (27). Subsequently, slides were washed in Tris-buffered saline and Polysorbate 20 (Menarini Diagnostics) and placed in Mayer's haematoxylin, dehydrated in graded ethanol, cleared in xylene and mounted in DPX (Sigma-Aldrich). After drying, slides were scanned $(\times 20$; Leica-Aperio AT2 ScanScope scanner; Leica Biosystems) and staining was quantified by image analysis software (Aperio ImageScope Positive Pixel Count Algorithm, version 9). Digital slides were processed by the software, with positively stained areas appearing orange/red and negative areas blue. Digital scores of three or above were considered positive for CD8 and CD68, while $\alpha$ SMA was categorised into high and low staining based on the mean value.

\section{Analysis of CLS}

CLS were identified in the archival and cMBC sections and aGC sections using anti-CD68 antibody, a pan macrophage marker used routinely by other groups to detect CLS (Iyengar et al. 2016). In order to quantify CLS objectively, image analysis software was used as described previously. CLS were defined by the complete encirclement of an adipocyte by orange/red-coloured macrophages, with quantification in Aperio ImageScope using the counter tool. The number of CLS in each area was summed to give the total number per case. cGC cases were not evaluated for presence of CLS, given the omission of adipose tissue from most of the TMA cores.

\section{Adipocyte measurement}

H\&E-stained sections from each case were scanned to create digital images $(\times 20$; Aperio ScanScope). Within each case, two random areas of adipose tissue were outlined based on the distance from the invading edge of the tumour. The area closest to the tumour (defined as less than $200 \mu \mathrm{m}$ ) was named the 'close' area, and the adipose area greater than $200 \mu \mathrm{m}$ was named the ' $\mathrm{far}^{\prime}$ area. In the aGC, areas of adipose were similarly identified as 'close' and 'far' based on their distance from stroma. Randomisation of adipocytes to be selected for measurement was achieved using RandomSpot (Wright et al. 2015). Twenty square boxes of 100 pixel diameter were overlaid on the outlined 'close' and 'far' areas of adipose. Each box was observed systematically and the adipocyte directly underneath the boxes was measured. Two measurements (horizontal and vertical, regardless of orientation) per adipocyte were taken, giving a total of 40 measurements of diameter per area of adipose.
The annotations were exported to Microsoft Excel, and then the mean diameter was calculated for each case. To exclude the possibility that fixation may have altered adipocyte size, frozen samples from three female BC cases were also evaluated as described.

\section{Statistical analysis}

All statistical analyses were carried out using IBM SPSS Statistics, version 24. The mean values for 'close' and 'far' adipose areas were calculated, and a paired $t$-test was conducted to calculate differences in each tissue type. Independent samples $t$-tests were conducted to identify the inter-group differences in mean adipocyte sizes. CLS were analysed using a Mann-Whitney $U$ test. Charité Cutoff Finder was used to calculate the optimal cut-off within the 'close' and 'far' group, above which would be considered 'large' adipocytes and below which would be considered 'small' adipocytes for that area (Budczies et al. 2012). Kaplan-Meier survival analysis was then conducted for the cMBC cases and plotted using GraphPad Prism, version 7.03. $P$ values of $<0.05$ were considered statistically significant, with cut-offs pre-determined before data analysis.

\section{Results}

\section{Adipocytes are smaller closer to the invading edge of the tumour}

Of the 49 cMBC cases, six were excluded for adipocyte counting due to the absence of adipose tissue. Therefore, the total number of cases for analysis of adipocyte diameter for $\mathrm{CMBC}$, aMBC and aGC was 43, 6 and 18, respectively. In the cMBC cohort, adipocytes closer to the tumour edge were consistently smaller; the mean far adipocyte diameter was $92.22 \pm 19.62 \mu \mathrm{m}$ and the mean close $66.74 \pm 15.11 \mu \mathrm{m}, \quad 25.48 \mu \mathrm{m} \pm 11.26 \mu \mathrm{m}$ larger $(95 \%$ CI $22.01-28.94 \mu \mathrm{m}, P<0.001)$. This trend was similar for aMBC cases with the diameter of far adipocytes $83.94 \pm 11.92 \mu \mathrm{m}$ and close $57.05 \pm 12.14 \mu \mathrm{m}$, $26.89 \mu \mathrm{m} \pm 10.00 \mu \mathrm{m}$ larger $(95 \%$ CI $16.40-37.38 \mu \mathrm{m}$, $P<0.001)$. While there was no difference in the size of close $(60.17 \pm 21.48 \mu \mathrm{m})$ and far $(63.90 \pm 16.45 \mu \mathrm{m})$ adipocytes in aGC cases $(P=0.16)$, there was a statistically significant difference between the mean diameters of far but not close adipocytes in aGC cases compared to those from archival $(P=0.012)$ and $\mathrm{cMBC}$ groups $(P<0.001)$. The results are depicted in Fig. 1 . To eliminate the possibility that adipocyte size may have been affected by processing to FFPE, size was also evaluated in frozen female breast 


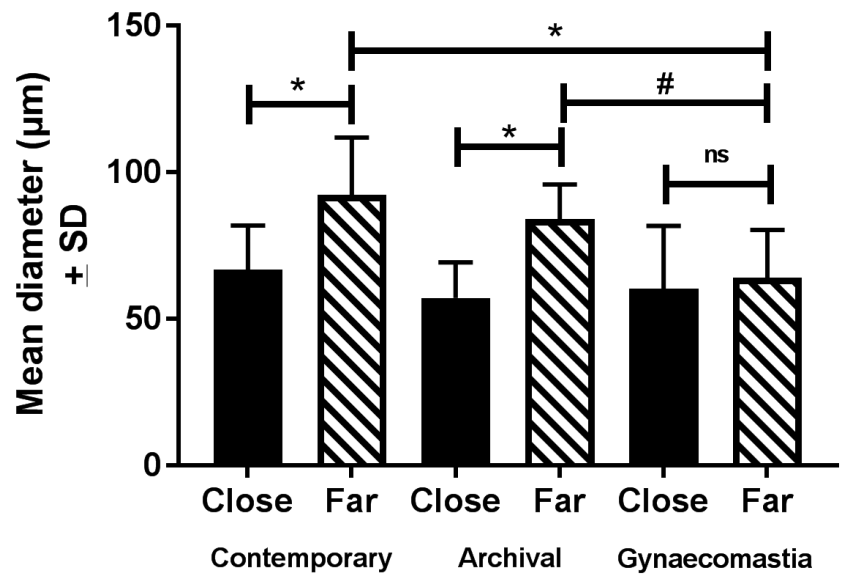

Figure 1

Mean difference in adipocyte diameter $(\mu \mathrm{m})$ between 'close' and 'far' areas for contemporary and archival male breast cancer and gynaecomastia. $P$ values refer to paired sample Student's $t$-test. *Denotes $P<0.001$; \#denotes $P=0.012$.

tissue with a similar smaller adipocyte diameter closer to the invasive tumour (Supplementary Fig. 1, see section on supplementary data given at the end of this article).

\section{CLS are more frequently observed in MBC than gynaecomastia}

As assessing CLS can be subjective, the Aperio-positive pixel count algorithm was utilised to facilitate counting.
An example is shown in Fig. 2A. CLS (arrows) were identified by the complete encirclement of an adipocyte by CD68-positive macrophages. CLS were frequently observed in the MBC cases. Of the 49 cMBC cases, 39 (80\%) displayed CLS. Additionally, CLS were observed in 5/6 $(83 \%)$ of aMBC cases. CLS were less frequent in aGC (11/18, $61 \%)$. The range varied enormously between cases, with $10 / 49$ (20.4\%) cMBC displaying no CLS at all, and up to 500 CLS observed in one aMBC case. Number of CLS was greater in both MBC cohorts compared to gynaecomastia cases (Table 2). No relationship was found between CLS number and adipocyte diameter (Fig. 2B), nor was there a difference when stratified into adipocytes with or without CLS (Fig. 2C). There were two obvious outliers in each of the contemporary and archival series where 500 and 496 CLS were recorded; when these were removed, there was a clear trend of increased numbers of CLS in both MBC compared to gynaecomastia (Fig. 2D).

\section{Inflammatory cell infiltrates in the tumour microenvironment influences MBC survival in the contemporary series}

Immunohistochemical staining of CD8, CD68 and $\alpha \mathrm{SMA}$ was quantified by image analysis (Supplementary Fig. 2). $\mathrm{T}$ cells were identified using CD8. Kaplan-Meier univariate survival analysis showed that higher levels of CD8 in the

A
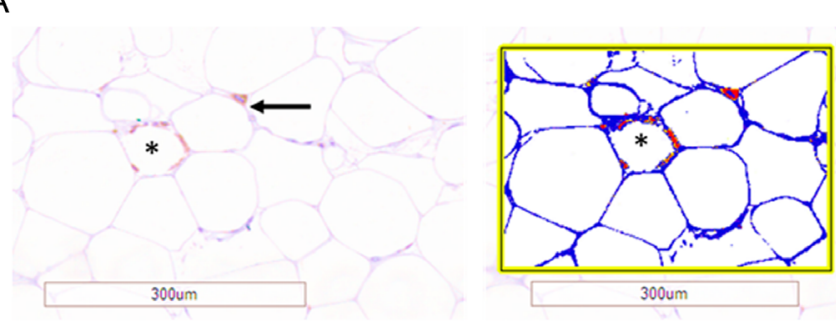

B

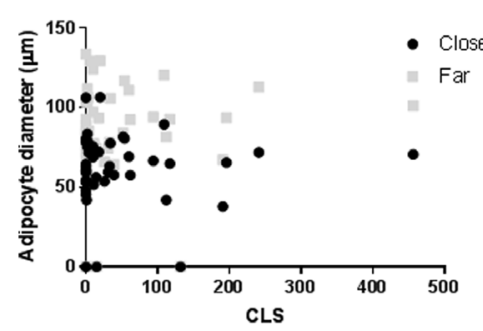

C

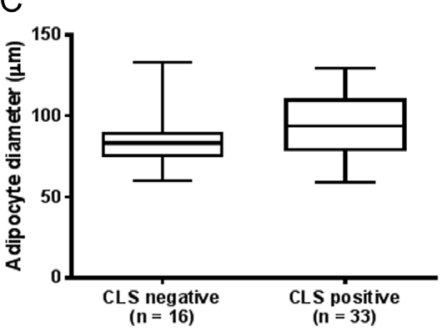

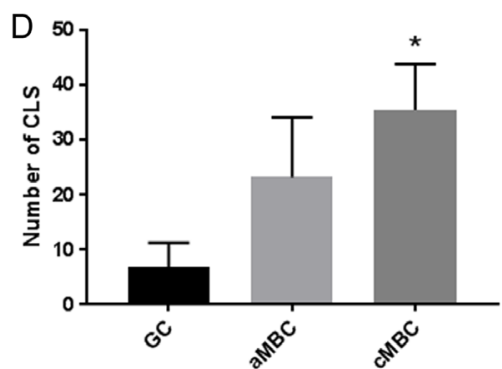

Figure 2

Example of CLS observed in MBC case with and without the Positive Pixel Count Algorithm applied (right and left images, respectively; (A). CLS is illustrated by the arrowhead and identified by the complete encirclement of an adipocyte by macrophages, coloured red by applying the algorithm and identified by the asterisk. Original magnification of scanned image $=20 \times$ (Aperio ScanScope). A scatter plot of adipocyte size and CLS density is shown in (B) and a box plot showing adipocyte size stratified in those with or without CLS is in (C). When two obvious outliers were removed, numbers of CLS showed a significant, stepwise increase in number from gynaecomastia through aMBC to cMBC (D). * $P<0.04$ vs gynaecomastia. CLS, crown-like structure; $\mathrm{CMBC}$, contemporary $\mathrm{MBC}$; $\mathrm{MBC}$, male breast cancer. 
Table 2 Crown-like structures are increased in male breast cancer compared to gynaecomastia.

\begin{tabular}{|c|c|c|c|}
\hline Pathology & $\begin{array}{l}\text { Median number } \\
\text { CLS (IQR) }\end{array}$ & CLS range & $\begin{array}{c}\text { Cases with } \\
\text { CLS (\%) }\end{array}$ \\
\hline cMBC & $18(59.5)$ & 0-496 & 80 \\
\hline aMBC & $26(161)$ & $0-500$ & 83 \\
\hline Gynaecomastia & $1(2.5)$ & $0-81$ & 61 \\
\hline
\end{tabular}

CLS, crown-like structure; CMBC, contemporary male breast cancer.

tumour stroma had a statistically significant negative effect on survival duration ( $P=0.016, \log$ rank; Fig. 3A). In addition to using CD68 to detect CLS, in these same sections, we also examined the impact of CD68-stained macrophages within the tumour stroma on survival. This showed that CD68 expression was significantly associated with reduced survival $(P=0.001, \log$ rank; Fig. 3B). Cancer-associated fibroblasts in the breast tumour microenvironment typically adopt a myofibroblast-like phenotype and express $\alpha$ SMA (Sappino et al. 1988); hence, we took advantage of this to identify these cells in $\mathrm{MBC}$ tissue sections. $\alpha \mathrm{SMA}$ was expressed in all cases but when categorised into high or low stroma, no significant effects were seen on survival ( $P=0.14, \log$ rank; Fig. $3 C)$. These analyses were not possible in the archival series due the lack of any follow up data.

\section{Discussion}

The aim of this study was to explore the adiposeinflammatory microenvironment of four cohorts of male breast tissue diagnosed in two different time periods, when obesity was rare (archival cohort) and more common (contemporary cohort).

We focused first on adipose tissue as adipocytes comprise a major part of the breast tumour stroma. Our data indicated that in both the archival and cMBC series, the size of adipocytes at the invading edge of the tumour were significantly smaller compared with those in distant stroma. This was not observed in benign male breast tissue, suggesting it may be a cancer-specific phenomenon. Concerned that this may be an artefact associated with tissue processing, we evaluated this on frozen cases of female BC, with identical results. It was also possible that the size differences in adipocytes may have resulted from the plane in which the sections were cut; however, this seems unlikely, as our data are supported by findings in female breast where adipocytes within/immediately adjacent to tumour tissue were also smaller in size compared to those in adjacent far breast tissue (DeFilippis et al. 2012, Fletcher et al. 2017). To our knowledge,
A

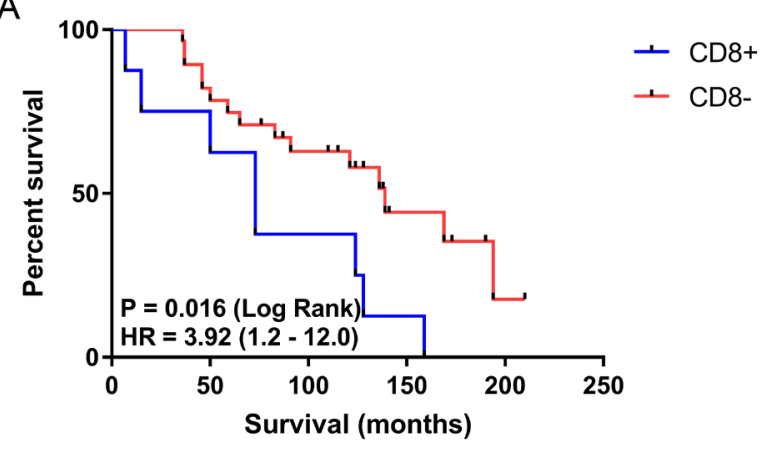

B

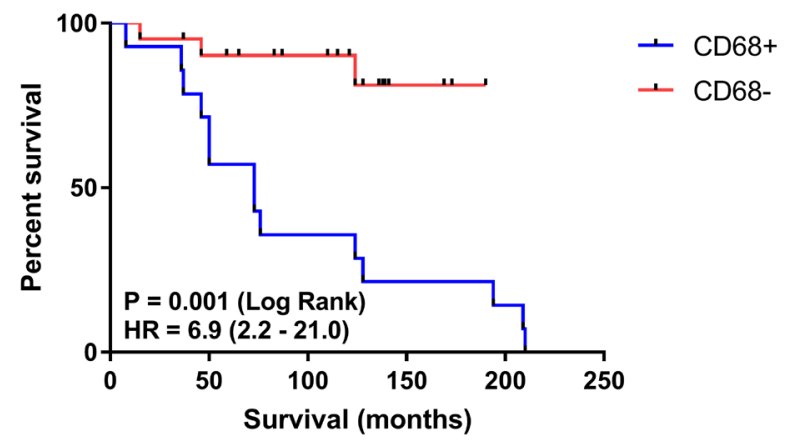

C

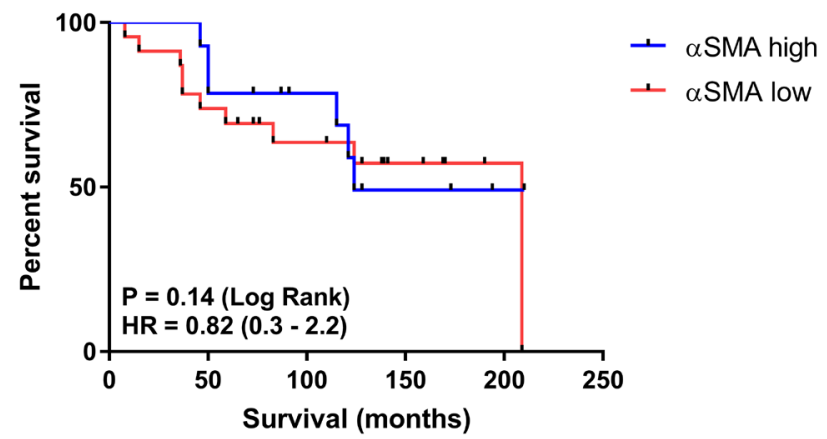

Figure 3

Kaplan-Meier survival analysis (log-rank test) of the in CMBC cohort showed CD8+ cells were significantly associated with reduced overall survival ( $P=0.016$; $\mathrm{A})$. The same association was also observed with $\mathrm{CD} 68$ positive cells $(P=0.001 ; B)$. No significant association was seen with the dichotomisation of $\alpha \mathrm{SMA}$ (C). CMBC, contemporary male breast cancer; $\mathrm{HR}$, hazard ratio.

this has not been reported in male breast tissue. The biological consequences are unknown; however, it may be related to adipocyte maturity since perilipin, a marker of adipocyte maturity, and adiponectin, a well-documented anti-proliferative marker, were both significantly reduced in BC adipocytes (Kang et al. 2005). Furthermore, co-culturing BC cell lines with mature but not immature adipocytes resulted in increased cell growth (Manabe et al. 2003). It remains to be elucidated if phenotypic changes observed in adipocytes close to and within breast 
tumours may result from bi-directional communication with the tumour cells. CLS are considered a reasonable hallmark of pathological obesity (Murano et al. 2008). Their presence and frequency within adipose tissue was examined in three of our male breast cohorts, and we developed a digital pathology algorithm to facilitate their quantification. This helped remove subjectivity associated with visual assessment of CLS employed by others (Koru-Sengul et al. 2016, Mullooly et al. 2017). CLS were observed in all three cohorts, however, were seen in a higher proportion of archival and cMBCs and at a greater frequency than in benign breast tissue. The numbers per case varied from none to up to several hundred, similar to that reported in female breast (Koru-Sengul et al. 2016, Mullooly et al. 2017). Removing two outliers from the archival and $\mathrm{CMBC}$ series showed the numbers of CLS ranked aMBC >cMBC> gynaecomastia. However, in contrast to reports in female BC (Vaysse et al. 2017), CLS number and adipocyte diameter did not correlate, even when stratified into adipocytes with or without CLS. Our cohort was roughly half of that analysed by Vaysse et al. (2017), which might explain the discrepancy or it could be due to gender-related differences. Further analysis of a larger male cohort, where full face sections are available, is required for confirmation.

Fibroblasts, endothelial cells and immune infiltrates reside within the tumour microenvironment, collectively comprising the stroma, which can influence growth and progression of neighbouring tumour cells. Using the cMBC series only, fibroblasts were identified by $\alpha \mathrm{SMA}$ (Sappino et al. 1988), then stratified into high and low $\alpha \mathrm{SMA}$-expression, determined on the basis of expression above and below the mean value obtained from the Aperio algorithm. There was no difference in outcome according to $\alpha$ SMA stratification. However, all cases in the contemporary series were $\mathrm{ER} \alpha+$. We have shown previously that a high proportion of stroma in ER $\alpha+$ male and female BC is associated with better survival (Downey et al. 2014), so this finding might be anticipated. We also examined the relationship of macrophages and $\mathrm{T}$ cells in the cMBC tumour microenvironment with survival. In line with studies in female BC, macrophages were associated with reduced survival (Leek et al. 1996, Campbell et al. 2011, Zhang et al. 2013, Bense et al. 2017).

We found high expression of CD8 in the MBC tumour microenvironment resulted in reduced survival. In women, the presence of CD8 is typically associated with better outcome in ER $\alpha$ - and to a lesser extent ER $\alpha+$ HER2 + BC (Liu et al. 2012, Ali et al. 2014); however, these subtypes are uncommon in $\mathrm{MBC}$, which is predominantly ER $\alpha+$ (Humphries et al. 2017). Indeed, our cohort was all ER $\alpha+$. Conversely, it has been demonstrated using TMAs that where the proportion of stroma is high, CD8 expression is low (Gujam et al. 2014). This is at odds with our study, although we used full face sections, not TMAs. Additionally, we noted CD8 positivity was heterogeneous; in some cases, this was entirely stromal CD8 while in others, it was restricted to tumour with some instances of positivity in both tumour and stroma (data not shown). In the BC field, international working groups have established guidelines in favour of assessment of TILs in H\&E-stained sections (Salgado et al. 2015, Hendry et al. 2017). As a result, scientists are gradually moving away from defining specific $\mathrm{T}$ cell populations identified by immunohistochemistry. A recent study assessed TIL density in 1196 MBCs, reporting that a lower density correlated with reduced overall survival (Vermeulen et al. 2017). Collectively, these results may indicate it is the repertoire of TILs, rather than specific subtypes, which are important in dictating $\mathrm{BC}$ outcome.

The main purpose of using the CD68 biomarker was to define CLS (Iyengar et al. 2016). While we acknowledge that this is sometimes regarded as marker of total macrophage population (Sousa et al. 2015), rather than defining specific M1 and M2 macrophage phenotypes, we used this to explore the possible significance of intratumoural CD68 expression on outcome. We found high CD68 expression was associated with poorer outcome, which parallels findings in female BC (Medrek et al. 2012, Zhang et al. 2013). As male breast tissue is rare, this precluded a more detailed analysis of other markers of macrophage activity such as CD163.

By analysing contemporary and $\mathrm{AMBC}$, alongside noncancerous gynaecomastia, which is often used as a MBC control (Alali et al. 2010), our data suggest that changes in the adipose-inflammatory microenvironment since the 1940s may be a contributing factor to the increase in MBC diagnosis over this time. Access to a unique cohort of archival male breast tissues has permitted this analysis. There have been considerable lifestyle changes during the time period that these samples were collected, one of which is the rising level of obesity. We do, however, acknowledge our study has limitations. The biggest limitation is the lack of recorded BMI data in any of the cohorts studied. Nevertheless, while high BMI has been shown to predict the presence of CLS in adipose tissue adjacent to the tumour in women (Vaysse et al. 2017), BMI does not always correlate with obesity, particularly, in athletes e.g. rugby players or American footballers whose large bulk contributes to high BMI. Additionally, we were 
only able to identify six cases of bona fide aMBC from our original cohort of 37. Typically, pathology departments do not store archival material for more than 30 years, making it challenging to obtain larger numbers for this type of work. Indeed two recent studies of $\mathrm{cMBC}$ are restricted in numbers, including 42 and 38 patients, respectively, (Cui et al. 2018, Turashvili et al. 2018), reflecting its rarity. Nevertheless, our study has uncovered novel and thoughtprovoking information, which should be considered as hypothesis generating for future work examining potential relationships between obesity and BC.

\section{Supplementary data}

This is linked to the online version of the paper at https://doi.org/10.1530/ ERC-17-0407.

\section{Declaration of interest}

The authors declare that there is no conflict of interest that could be perceived as prejudicing the impartiality of the research reported.

\section{Funding}

This study was funded by the British Division of the International Academy of Pathology (to T L), Breast Cancer Now (TB2016LEE; to V S) and Yorkshire Cancer Research (L378; to V S).

\section{Acknowledgements}

The authors wish to acknowledge the role of the Breast Cancer Now Tissue Bank in collecting and making available the samples used in the generation of this publication. Thanks to $\mathrm{Dr}$ Gordon Hutchins for the helpful comments.

\section{References}

Alali L, Honarpisheh H, Shaaban A \& Speirs V 2010 Conditions of the male breast: gynaecomastia and male breast cancer (Review). Molecular Medicine Reports 3 21-26. (https://doi.org10.3892/ mmr_00000213)

Ali HR, Provenzano E, Dawson SJ, Blows FM, Liu B, Shah M, Earl HM, Poole CJ, Hiller L, Dunn JA, et al. 2014 Association between CD8+ T-cell infiltration and breast cancer survival in 12,439 patients. Annals of Oncology 25 1536-1543. (https://doi.org/10.1093/annonc/ mdu191)

Anderson WF, Jatoi I, Tse J \& Rosenberg PS 2010 Male breast cancer: a population-based comparison with female breast cancer. Journal of Clinical Oncology 28 232-239. (https://doi.org/10.1200/ JCO.2009.23.8162)

Balkwill F, Charles KA \& Mantovani A 2005 Smoldering and polarized inflammation in the initiation and promotion of malignant disease. Cancer Cell 7 211-217. (https://doi.org/10.1016/j.ccr.2005.02.013)

Bannayan GA \& Hajdu SI 1972 Gynecomastia: clinicopathologic study of 351 cases. American Journal of Clinical Pathology 57 431-437. (https://doi.org/10.1093/ajcp/57.4.431)

Bense RD, Sotiriou C, Piccart-Gebhart MJ, Haanen JB, van Vugt MA, de Vries EG, Schroder CP \& Fehrmann RS 2017 Relevance of tumorinfiltrating immune cell composition and functionality for disease outcome in breast cancer. Journal of the National Cancer Institute 109 djw192. (https://doi.org/10.1093/jnci/djw192)

Budczies J, Klauschen F, Sinn BV, Gyorffy B, Schmitt WD, Darb-Esfahani S \& Denkert C 2012 Cutoff Finder: a comprehensive and straightforward Web application enabling rapid biomarker cutoff optimization. PLOS ONE 7 e51862. (https://doi.org/10.1371/journal.pone.0051862)

Campbell MJ, Tonlaar NY, Garwood ER, Huo D, Moore DH, Khramtsov AI, Au A, Baehner F, Chen Y, Malaka DO, et al. 2011 Proliferating macrophages associated with high grade, hormone receptor negative breast cancer and poor clinical outcome. Breast Cancer Research and Treatment 128 703-711. (https://doi.org/10.1007/ s10549-010-1154-y)

Chen GC, Chen SJ, Zhang R, Hidayat K, Qin JB, Zhang YS \& Qin LQ 2016 Central obesity and risks of pre- and postmenopausal breast cancer: a dose-response meta-analysis of prospective studies. Obesity Reviews 17 1167-1177. (https://doi.org/10.1111/obr.12443)

Cinti S, Mitchell G, Barbatelli G, Murano I, Ceresi E, Faloia E, Wang S, Fortier M, Greenberg AS \& Obin MS 2005 Adipocyte death defines macrophage localization and function in adipose tissue of obese mice and humans. Journal of Lipid Research 46 2347-2355. (https:// doi.org/10.1194/jlr.M500294-JLR200)

Cui Q, Kong D, Li Z, Ahiable P, Wang K, Wu K \& Wu G 2018 Dachshund 1 is differentially expressed between male and female breast cancer: a matched case-control study of clinical characteristics and prognosis. Clinical Breast Cancer [epub]. (https://doi. org/10.1016/j.clbc.2018.01.011)

De Pergola G \& Silvestris F 2013 Obesity as a major risk factor for cancer. Journal of Obesity 2013 11. (https://doi.org/10.1155/2013/291546)

DeFilippis RA, Chang H, Dumont N, Rabban JT, Chen YY, Fontenay GV, Berman HK, Gauthier ML, Zhao J, Hu D, et al. 2012 CD36 repression activates a multicellular stromal program shared by high mammographic density and tumor tissues. Cancer Discovery 2 826-839. (https://doi.org/10.1158/2159-8290.CD-12-0107)

Downey CL, Simpkins SA, White J, Holliday DL, Jones JL, Jordan LB, Kulka J, Pollock S, Rajan SS, Thygesen HH, et al. 2014 The prognostic significance of tumour-stroma ratio in oestrogen receptor-positive breast cancer. British Journal of Cancer 110 1744-1747. (https://doi. org/10.1038/bjc.2014.69)

Dowsett T, Verghese E, Pollock S, Pollard J, Heads J, Hanby A \& Speirs V 2014 The value of archival tissue blocks in understanding breast cancer biology. Journal of Clinical Pathology 67 272-275. (https://doi. org/10.1136/jclinpath-2013-201854)

Fletcher SJ, Sacca PA, Pistone-Creydt M, Colo FA, Serra MF, Santino FE, Sasso CV, Lopez-Fontana CM, Caron RW, Calvo JC, et al. 2017 Human breast adipose tissue: characterization of factors that change during tumor progression in human breast cancer. Journal of Experimental and Clinical Cancer Research 36 26. (https://doi. org/10.1186/s13046-017-0494-4)

Gujam FJ, Edwards J, Mohammed ZM, Going JJ \& McMillan DC 2014 The relationship between the tumour stroma percentage, clinicopathological characteristics and outcome in patients with operable ductal breast cancer. British Journal of Cancer 111 157-165. (https://doi.org/10.1038/bjc.2014.279)

Gwak JM, Jang MH, Kim DI, Seo AN \& Park SY 2015 Prognostic value of tumor-associated macrophages according to histologic locations and hormone receptor status in breast cancer. PLOS ONE 10 e0125728. (https://doi.org/10.1371/journal.pone.0125728)

Hendry S, Salgado R, Gevaert T, Russell PA, John T, Thapa B, Christie M, van de Vijver K, Estrada MV, Gonzalez-Ericsson PI, et al. 2017 Assessing tumor-infiltrating lymphocytes in solid tumors: a practical review for pathologists and proposal for a standardized method from the International Immunooncology Biomarkers Working Group: Part 1: assessing the host immune response, TILs in invasive breast carcinoma and ductal carcinoma in situ, metastatic tumor deposits and areas for further research. Advances in Anatomic Pathology 24 235-251. (https://doi.org/10.1097/PAP.0000000000000162) (c) 2018 Society for Endocrinology Published by Bioscientifica Ltd. Printed in Great Britain 
Humphries MP, Jordan VC \& Speirs V 2015 Obesity and male breast cancer: provocative parallels? BMC Medicine 13 134. (https://doi. org/10.1186/s12916-015-0380-x)

Humphries MP, Sundara Rajan S, Honarpisheh H, Cserni G, Dent J, Fulford L, Jordan LB, Jones JL, Kanthan R, Litwiniuk M, et al. 2017 Characterisation of male breast cancer: a descriptive biomarker study from a large patient series. Scientific Reports 7 45293. (https://doi. org/10.1038/srep45293)

Iyengar NM, Zhou XK, Gucalp A, Morris PG, Howe LR, Giri DD, Morrow M, Wang H, Pollak M, Jones LW, et al. 2016 Systemic correlates of white adipose tissue inflammation in early-stage breast cancer. Clinical Cancer Research 22 2283-2289. (https://doi. org/10.1158/1078-0432.CCR-15-2239)

Johnson AR, Milner JJ \& Makowski L 2012 The inflammation highway: metabolism accelerates inflammatory traffic in obesity. Immunological Reviews 249 218-238. (https://doi.org/10.1111/j.1600-065X.2012. 01151.x)

Kang JH, Lee YY, Yu BY, Yang BS, Cho KH, Yoon DK \& Roh YK 2005 Adiponectin induces growth arrest and apoptosis of MDA-MB-231 breast cancer cell. Archives of Pharmacal Research 28 1263-1269. (https://doi.org/10.1007/BF02978210)

Koru-Sengul T, Santander AM, Miao F, Sanchez LG, Jorda M, Gluck S, Ince TA, Nadji M, Chen Z, Penichet ML, et al. 2016 Breast cancers from black women exhibit higher numbers of immunosuppressive macrophages with proliferative activity and of crown-like structures associated with lower survival compared to non-black Latinas and Caucasians. Breast Cancer Research and Treatment 158 113-126. (https://doi.org/10.1007/s10549-016-3847-3)

Leek RD, Lewis CE, Whitehouse R, Greenall M, Clarke J \& Harris AL 1996 Association of macrophage infiltration with angiogenesis and prognosis in invasive breast carcinoma. Cancer Research 56 4625-4629.

Liu S, Lachapelle J, Leung S, Gao D, Foulkes WD \& Nielsen TO 2012 CD8+ lymphocyte infiltration is an independent favorable prognostic indicator in basal-like breast cancer. Breast Cancer Research 14 R48. (https://doi.org/10.1186/bcr3148)

Loi S, Sirtaine N, Piette F, Salgado R, Viale G, Van Eenoo F, Rouas G, Francis P, Crown JP, Hitre E, et al. 2013 Prognostic and predictive value of tumor-infiltrating lymphocytes in a phase III randomized adjuvant breast cancer trial in node-positive breast cancer comparing the addition of docetaxel to doxorubicin with doxorubicin-based chemotherapy: BIG 02-98. Journal of Clinical Oncology 31 860-867. (https://doi.org/10.1200/JCO.2011.41.0902)

Manabe Y, Toda S, Miyazaki K \& Sugihara H 2003 Mature adipocytes, but not preadipocytes, promote the growth of breast carcinoma cells in collagen gel matrix culture through cancer-stromal cell interactions. Journal of Pathology 201 221-228. (https://doi. org/10.1002/path.1430)

Medrek C, Ponten F, Jirstrom K \& Leandersson K 2012 The presence of tumor associated macrophages in tumor stroma as a prognostic marker for breast cancer patients. BMC Cancer 12 306. (https://doi. org/10.1186/1471-2407-12-306)

Mullooly M, Yang HP, Falk RT, Nyante SJ, Cora R, Pfeiffer RM, Radisky DC, Visscher DW, Hartmann LC, Carter JM, et al. 2017 Relationship between crown-like structures and sex-steroid hormones in breast adipose tissue and serum among postmenopausal breast cancer patients. Breast Cancer Research 19 8. (https://doi.org/10.1186/ s13058-016-0791-4)

Murano I, Barbatelli G, Parisani V, Latini C, Muzzonigro G, Castellucci M \& Cinti S 2008 Dead adipocytes, detected as crownlike structures, are prevalent in visceral fat depots of genetically obese mice. Journal of Lipid Research 49 1562-1568. (https://doi. org/10.1194/jlr.M800019-JLR200)

Salgado R, Denkert C, Demaria S, Sirtaine N, Klauschen F, Pruneri G, Wienert S, Van den Eynden G, Baehner FL, Penault-Llorca F, et al. 2015 The evaluation of tumor-infiltrating lymphocytes (TILs) in breast cancer: recommendations by an International TILs Working Group 2014. Annals of Oncology 26 259-271. (https://doi. org/10.1093/annonc/mdu450)

Sappino AP, Skalli O, Jackson B, Schurch W \& Gabbiani G 1988 Smoothmuscle differentiation in stromal cells of malignant and nonmalignant breast tissues. International Journal of Cancer 41 707-712. (https://doi.org/10.1002/ijc.2910410512)

Savas P, Salgado R, Denkert C, Sotiriou C, Darcy PK, Smyth MJ \& Loi S 2016 Clinical relevance of host immunity in breast cancer: from TILs to the clinic. Nature Reviews Clinical Oncology 13 228-241. (https:// doi.org/10.1038/nrclinonc.2015.215)

SEER 2014 Surveillance Epidemiology and End Results (SEER). Program Surveillance Research Program, Surveillance Systems Branch, 2015. NCI. (available from: www.seer.cancer.gov). Accessed on 8 July 2014.

Sousa S, Brion R, Lintunen M, Kronqvist P, Sandholm J, Monkkonen J, Kellokumpu-Lehtinen PL, Lauttia S, Tynninen O, Joensuu H, et al. 2015 Human breast cancer cells educate macrophages toward the M2 activation status. Breast Cancer Research 17 101. (https://doi. org/10.1186/s13058-015-0621-0)

Speirs V \& Shaaban AM 2009 The rising incidence of male breast cancer. Breast Cancer Research and Treatment 115 429-430. (https://doi. org/10.1007/s10549-008-0053-y)

Turashvili G, Gonzalez-Loperena M, Brogi E, Dickler M, Norton L, Morrow M \& Wen HY 2018 The 21-gene recurrence score in male breast cancer. Annals of Surgical Oncology 25 1530-1535. (https://doi. org/10.1245/s10434-018-6411-z)

Vaysse C, Lomo J, Garred O, Fjeldheim F, Lofteroed T, Schlichting E, McTiernan A, Frydenberg H, Husoy A, Lundgren S, et al. 2017 Inflammation of mammary adipose tissue occurs in overweight and obese patients exhibiting early-stage breast cancer. NPJ Breast Cancer 3 19. (https://doi.org/10.1038/s41523-017-0015-9)

Vermeulen MA, Slaets L, Cardoso F, Giordano SH, Tryfonidis K, van Diest PJ, Dijkstra NH, Schröder CP, van Asperen CJ, Linderholm B, et al. 2017 Pathological characterisation of male breast cancer: results of the EORTC 10085/TBCRC/BIG/NABCG International Male Breast Cancer Program. European Journal of Cancer 82 219-227. (https://doi. org/10.1016/j.ejca.2017.01.034)

Wright A, Grabsch H \& Treanor D 2015 RandomSpot: a web-based tool for systematic random sampling of virtual slides. Journal of Pathology Informatics 6 8. (https://doi.org/10.4103/2153-3539.151906)

Yamaguchi R, Tanaka M, Yano A, Tse GM, Yamaguchi M, Koura K, Kanomata N, Kawaguchi A, Akiba J, Naito Y, et al. 2012 Tumorinfiltrating lymphocytes are important pathologic predictors for neoadjuvant chemotherapy in patients with breast cancer. Human Pathology 43 1688-1694. (https://doi.org/10.1016/j. humpath.2011.12.013)

Zhang Y, Cheng S, Zhang M, Zhen L, Pang D, Zhang Q \& Li Z 2013 High-infiltration of tumor-associated macrophages predicts unfavorable clinical outcome for node-negative breast cancer. PLoS ONE 8 e76147. (https://doi.org/10.1371/journal.pone.0076147)

Zhao X, Qu J, Sun Y, Wang J, Liu X, Wang F, Zhang H, Wang W, Ma X, Gao X, et al. 2017 Prognostic significance of tumor-associated macrophages in breast cancer: a meta-analysis of the literature. Oncotarget 8 30576-30586. (https://doi.org/10.18632/ oncotarget.23371)

Received in final form 9 April 2018

Accepted 8 May 2018

Accepted Preprint published online 9 May 2018 (c) 2018 Society for Endocrinology Published by Bioscientifica Ltd. Printed in Great Britain 